\title{
A Review on Post Stroke Shoulder Pain Management
}

\author{
MD. SHAHIDUR RAHMAN ${ }^{1}$
}

\begin{abstract}
:
Shoulder pain is critically important obstacle to functional recovery in most of the stroke sufferers. Hemiplegic shoulder pain causes considerable distress and reduced activity and can markedly hinder rehabilitation. The etiology of hemiplegic shoulder pain is probably multifactorial. The ideal management of hemiplegic stroke pain is prevention. For prophylaxis to be effective, it must begin immediately after the stroke. Awareness of potential injuries to the shoulder joint reduces the frequency of shoulder pain after stroke. The multidisciplinary team, patients, and care givers should be provided with instructions on how to avoid injuries to the affected limb. Shoulder strapping may be used to prevent shoulder pain. Over arm slings should be avoided. Treatment should include analgesics heat or cold therapy, electrical stimulation and pain free exercise as well. This review was done to find the recent developments in post-stroke shoulder pain management by extracting the published articles in this topic. The ultimate objectives were to delineate most rational and effective treatment options for post-stroke shoulder pain.
\end{abstract}

Introduction:

Shoulder pain has been reported to be one of the most common complications after stroke $e^{1,2}$. The incidence varies between $9 \%$ and $40 \%$ depending on patient group and study design ${ }^{1-4}$. Different studies have used various terms for shoulder pain, e.g., shoulder pain in hemiplegia ${ }^{5-8}$, hemiplegic shoulder pain ${ }^{9}$,and post stroke shoulder pain. Sometimes, it is unclear whether only proximal pain in the arm was assessed or if also more distal arm pain was included ${ }^{10}$. Shoulder pain hinders rehabilitation, is an important contributor to length of hospital stay ${ }^{11}$,and has been associated with depression ${ }^{4}$ and decreased quality of life ${ }^{12}$.Several factors have been related to shoulder pain after stroke such as paralysis $3,4,13,14$,restricted range of motion in the shoulder ${ }^{5,6,13}$, spasticity ${ }^{7,8}$, right hemispheric cerebrovascular lesion and left hemiplegia ${ }^{6,8}$, sensory abnormalities ${ }^{4,8}$, diabetes mellitus $^{3}$, low Barthel Index score ${ }^{11}$, and inappropriate handling of the patient ${ }^{9}$. Recovery from shoulder pain may occur in $80 \%{ }^{4}$. A common sequel of stroke is hemiplegic shoulder pain that can hamper functional recovery and subsequently lead to disability. Poduri reports that hemiplegic shoulder pain can begin as early as 2 weeks post stroke but typically occurs within 2-3 months post- stroke ${ }^{15}$. The cause of hemiplegic shoulder pain is the subject of considerable controversy. The following processes have all been postulated as causes of a painful hemiplegic shoulder: glenohumeral subluxation, spasticity of shoulder muscles, impingement, soft tissue trauma, rotator cuff tears, glenohumeral capsulitis, bicipital tendinitis, and shoulder hand syndrome. The etiology of hemiplegic shoulder pain is probably multifactorial. Chae and coauthors indicated that the amount of motor recovery is related to the degree of initial severity and the amount of time before voluntary movements are initiated ${ }^{16,17}$.

\section{Factors contributing to pain}

Subluxation and spasticity: Wanklyn and coauthors found no association between the severity of subluxation and the degree of pain ${ }^{18}$.Numerous cases of subluxation without pain have been documented, as have cases of a painful shoulder without subluxation. Spasticity is defined as a velocity-sensitive disorder of motor function causing increased resistance to the passive stretching of muscles and hyperactive muscle stretch reflexes. Van Ouwenaller and colleagues identified spasticity as a prime factor and one of the most common causes of shoulder pain in patients with

1. Associate Professor ,Physical Medicine and Rehabilitation ,Bangabandhu Sheikh Mujib Medical University 
hemiplegia ${ }^{19}$. Compared with patients who have flaccidity, patients with spasticity seem to experience a much higher incidence of shoulder pain, which is thought to result from muscle imbalance.

\section{Complex regional pain syndrome}

The incidence of Complex regional pain syndrome (CRPS) varies in the literature. Davis and coauthors reported that CRPS occurs in $12.5 \%$ of patients who have had a stroke, while Chalsen and colleagues reported the incidence to be $61 \% 20$. Onset of CRPS is within 3 months post stroke and rarely after 5 months post stroke. In a study, Davis and coworkers demonstrated that of those patients who developed CRPS, $65 \%$ had done so by 3 months post stroke, and $98 \%$ had done so by 5 months post stroke 21 .

\section{Adhesive capsulitis}

Glenohumeral capsulitis is postulated to play an important role in hemiplegic shoulder pain. Patients usually present with pain and limited passive movement of the shoulder, especially external rotation and abduction. Joynt reported that adhesive changes may reflect a later stage in the recovery process, when chronic irritation or injury, inflammation, or lack of movement eventually results in adhesions ${ }^{22}$.

Patients with hemiplegia who have their flaccid arm in an unsupported, dependent position or patients who have been inappropriately transferred by pulling on the arm, tend to be at increased risk for traction neuropathy. Kaplan suggested that plexus injury should be considered in a patient who has atypical return of distal function ${ }^{23}$.

\section{Neglect}

Joynt reported that neglect may lead to increased trauma or disturbed perception of the quality of the pain, thereby producing a sensation of pain without the usual pathology 22 .Snels and coauthors found that on numerous occasions, patients with sensory deficits, visual field deficits, or neglect more commonly experienced recurrent injuries of the shoulder, possibly contributing to capsulitis ${ }^{24}$.

Diagnosis: Diagnosis can be confirmed through history of stroke and excluding pre stroke pathology.
A Common findings of the shoulder and upper extremity (UE) reported by patients with hemiplegia include painful restricted range of motion, mild swelling and tenderness.

Management update: Most effective and rational treatment options should address the factors contributing to pain first, the pain and function.

\section{Glenohumeral subluxation}

Treatment of subluxation by reduction remains a controversial means of controlling shoulder pain. Slings, arm boards, troughs, and lap trays have not proven to be effective and, in some cases, may result in overcorrection. Sling use also may cause lateral subluxation, impair proprioception, interfere with functional activities, or promote undesirable synergy patterns; furthermore, sling use may not prove beneficial in preventing shoulder subluxation. Neuromuscular electrical stimulation (NMES), has proven moderately successful in the prevention and treatment of subluxation ${ }^{25,26}$. Yu and colleagues demonstrated that NMES causes substantial reduction in subluxation and, possibly, enhancement of motor recovery and reduction of shoulder pain ${ }^{18,27 .}$

Spasticity management: The mainstay of treatment for spasticity begins with physical therapy and the use of ROM and stretching exercises, Overaggressive stretching or ROM should be avoided during the rehabilitation process ${ }^{28}$. Proper positioning also is used as a means of controlling spasticity, by suppressing the evolution of synergy patterns. Botulinum toxin also is preferred when the desired outcome is for slower onset with shorter duration ${ }^{29,30}$. This procedure is sometimes used when the subscapularis and pectoralis major muscles require nerve block. Chironna and Hecht felt that motor block to nerves innervating internal rotators would help relieve the pain caused by internal rotation synergy 31 .

\section{Complex regional pain syndrome}

Treatment options are numerous and physical therapy is the cornerstone. ROM exercises, optimal positioning of the limb, and the avoidance of painful stimuli are all suggested. Other treatments might include non-steroidal anti-inflammatory drugs (NSAIDs), modalities such as electrical nerve 
stimulation or ultrasonography ), a short course of oral steroids, or a ganglion block.

\section{Adhesive capsulitis}

Treatment of adhesive capsulitis usually involves therapeutic exercise, manual mobilization exercises, analgesics, and possibly steroid injections. Treatment for traction injuries is limited to the use of supportive care until the return of function.

\section{Subacromial bursitis.}

Early treatment with physical modalities, NSAIDs, steroid injections, and ROM exercises is advocated for the reduction of symptoms and prevention of later complications.

\section{Neglect-related pain}

Treatment options suggested by Lorish and colleagues include caloric stimulation, prism glasses, visuospatial cueing, computer-assisted training, and compensatory strategies ${ }^{32}$.

Physiotherapy: Physiotherapy has been used in the treatment of hemiplegic shoulder pain ${ }^{33}$. There are two major approaches to therapy in this field: those that focus on the problem as a localized mechanical one; and those that view the problem as a neurological one. Local treatments used have included heat and cold therapy $34,35,36$. Slings and shoulder supports have also been used ${ }^{37,38}$. Other physiotherapy approaches include those of Bobath, Brunnstrom, and proprioceptive neuromuscular facilitation. Until recently, the evidence for the effectiveness of these methods of physiotherapy has been poor ${ }^{34}$.

In patients with hemiplegia, ROM of the shoulder is usually lost early, so Hanger and colleagues recommended that preventive treatments begin as soon as possible, usually within the first $1-2$ days post stroke ${ }^{39}$.Arm support and preservation of joint ROM is performed through early passive motion.

Biofeedback: Biofeedback is based on muscular relaxation and/or reeducation by verbal, visual, sensory, or auditory responses. Biofeedback is used in an attempt to relax the antagonist muscles, subsequently allowing the opposed agonists to function more effectively. In order to reeducate the upper extremity, the spastic scapular and glenohumeral antagonist muscles need to be released in order for the agonists to work more proficiently.

A common type of biofeedback, which was first introduced in 1960, involves the use of EMG for neuromuscular reeducation. Overall, trials involving EMG biofeedback have shown mixed results, and its cost-effectiveness is uncertain. However, a metaanalysis by Schleenbaker and Mainous showed it to be an effective tool for neuromuscular reeducation and improving functional outcomes in stroke patients with hemiplegia ${ }^{40}$.

\section{Proprioceptive neuromuscular facilitation} Developed by Kabat, Knott, and Voss, proprioceptive neuromuscular facilitation (PNF) involves repeated muscle activation of the limbs by quick stretching, traction, approximation, and maximal manual resistance in functional directions (ie, spiral and diagonal patterns) to assist with motor relearning and increasing sensory input. Lorish and coauthors have considered it to be an optimal method of stretching in patients with hemiplegia ${ }^{32}$.Numerous clinical trials have not proven that application of any one facilitative approaches improves patient outcome over conventional therapy ${ }^{41-46}$.

\section{Constraint-induced movement therapy}

Constraint-induced movement therapy (CIT) is a family of therapies that induce patients who have had a stroke to greatly increase the amount and quality of movement of their paretic limb, in turn improving function. CIT is based on the theory of "learned nonuse," first described by Wolf and colleagues $^{47}$ and later by Taub and coauthors ${ }^{48}$. Researchers subsequently concluded that the use of CIT proved to be an effective means of restoring substantial motor function in chronic stroke patients.

\section{Prevention}

Without appropriate care, patients with hemiplegia have an increased risk of developing numerous shoulder complications, including nerve pressure palsies, nerve traction injuries, rotator cuff pathology, capsulitis, impingement syndromes, or subluxation. Strapping also has been studied as a 
means for shoulder support. Theoretically, it should support the glenohumeral joint or reduce subluxation while allowing the upper extremity to move freely.

A study by Hanger and colleagues concluded that strapping the shoulder did not significantly preserve ROM or reduce the prevalence of subluxation over a 6-week trial, even when done concomitantly with standard physical therapy ${ }^{39}$.

\section{Prognosis}

Carr and Kenney reported that about two thirds of all stroke survivors will be disabled, up to $50 \%$ will be severely disabled, and $10-15 \%$ will require institutional care ${ }^{49}$.Motor weakness also is reported in $50-80 \%$ of post stroke survivors. Brandstater reported that most spontaneous recovery of voluntary motor function occurs in the first 2-3 months following stroke. However, it can occur years later ${ }^{50}$.

Cailliet reported an unfavorable prognosis for complete upper extremity motor recovery if the flaccid stage lasts longer than 2 weeks, ${ }^{51}$ Other unfavorable predictors in estimating functional recovery include excessive spasticity and impaired sensation and perception, ${ }^{52}$ Depression also can contribute to unfavorable outcome, with Wanklyn and coauthors reporting a $22-27 \%$ incidence within the first few weeks post stroke ${ }^{53}$.

Conclusion: Hemiplegic shoulder pain affects stroke outcome in a negative way. It interferes with recovery after a stroke: it can cause considerable distress and reduced activity and can markedly hinder rehabilitation. Hemiplegic shoulder pain has been associated with prolonged hospital stay and poor recovery of arm function in the first 12 weeks after stroke. Depression and reduced quality of life among patients after stroke with pain has been described, but it has not been clearly established if these factors are directly related to the severity of pain, higher degree of impairment, or other factors. Important outcomes include pain relief, improved passive and active range of motion and arm function Indications for surgery in patients with hemiplegic shoulder pain include failure of conservative treatment and pain of such intensity that it interferes with skin hygiene or prevents participation in rehabilitation.

\section{References:}

1. Langhorne $P$, Stott DJ, Robertson L, MacDonald J, Jones L, McAlpine C, D. Medical complications after stroke: a multicenter study. Stroke.2000; 31: 1223-29.

2. McLean DE. Medical complications experienced by a cohort of stroke survivors during inpatient, tertiary-level stroke rehabilitation. Arch Phys Med Rehabil.2004; 85: 466-69.

3. Ratnasabapathy $\mathrm{Y}$, Broad J, Baskett J, Pledger M, Marshall J, Bonita R. Shoulder pain in people with a stroke: a populationbased study. Clin Rehabil.2003; 17: 304-11.

4. Gamble GE, Barberan E, Laasch HU, Bowsher D, Tyrrell PJ, Jones AK. Post-stroke shoulder pain: a prospective study of the association and risk factors in 152 patients from a consecutive cohort of 205 patients presenting with stroke. Eur J Pain. 2002; 6: 467-74.

5. Bohannon RW, Larkin PA, Smith MB, Horton MG. Shoulder pain in hemiplegia: statistical relationship with five variables. Arch Phys Med Rehabil.1986; 67: 514-76.

6. Joynt RL. The source of shoulder pain in hemiplegia. Arch Phys Med Rehabil.1992; 73 : 409-13.

7. Van Ouwenaller C, Laplace PM, Chantraine A. Painful shoulder in hemiplegia. Arch Phys Med Rehabil.1986; 67: 23-26.

8. Poulin de Courval L, Barsauskas A, Berenbaum B, Dehaut F, Dussault R, Fontaine FS et at. Painful shoulder in the hemiplegic and unilateral neglect. Arch Phys Med Rehabil.1990; 71: 673-76.

9. Wanklyn P, Forster A, Young J. Hemiplegic shoulder pain (hsp): natural history and investigation of associated features. Disabil Rehabil.1996; 18: 497-501.

10. Price CIM. Treatment of shoulder and upper limb pain after stroke: an obstacle course for evidence-based practice. Reviews in Clinical Gerontology.2003; 13: 321-33. 
11. Roy CW, Sands MR, Hill LD, Harrison A, Marshall $S$. The effect of shoulder pain on outcome of acute hemiplegia.ClinRehabil.1995; 9: 21-7.

12. Widar M, Ahlström G, Ek AC. Health-related quality of life in persons with long-term pain after a stroke. J Clin Nurs.2004; 13: 497505.

13. Roy CW, Sands MR, Hill LD. Shoulder pain in acutely admitted hemiplegics. Clin Rehabil.1994; 8: 334-40.

14. Jespersen HF, Jorgensen HS, Nakayama H, Olsen TS. Shoulder pain after a stroke. Int J Rehabil Res. 1995; 18: 273-6.

15. Poduri KR. Shoulder pain in stroke patients and its effect on rehabilitation. J Stroke Cerebrovascular Dis. 1993;3:261-6.

16. Chae J, Bethoux F, Bohine T, Dobos L, Davis T, Friedl A. Neuromuscular stimulation for upper extremity motor and functional recovery in acute hemiplegia. Stroke. 1998;29(5):975-9.

17. Chae J, Yu DT, Walker ME, Kirsteins A, Elovic $E P$, Flanagan $S R$, et al. Intramuscular electrical stimulation for hemiplegic shoulder pain: a 12-month follow-up of a multiplecenter, randomized clinical trial. Am J Phys Med Rehabil. 2005;84(11):832-42.

18. Yu DT, Chae J, Walker ME, Hart RL, Petroski GF. Comparing stimulation-induced pain during percutaneous (intramuscular) and transcutaneous neuromuscular electric stimulation for treating shoulder subluxation in hemiplegia. Arch Phys Med Rehabil. 2001;82(6):756-60.

19. Van Ouwenaller C, Laplace PM, Chantraine A. Painful shoulder in hemiplegia. Arch Phys Med Rehabil. Jan 1986;67(1):23-6.

20. Teasell RW. The painful hemiplegic shoulder. Physical Medicine and Rehabilitation: State of the Art Reviews. 1998;12(3):489-500.

21. Davis SW, Petrillo CR, Eichberg RD, Chu DS. Shoulder-hand syndrome in a hemiplegic population: a 5-year retrospective study. Arch Phys Med Rehabil. 1977; 58(8):353-6.
22. Joynt RL. The source of shoulder pain in hemiplegia. Arch Phys Med Rehabil. 1992;73(5):409-13.

23. Kaplan MC. Hemiplegic shoulder pain-early prevention and rehabilitation. West J Med. Feb 1995;162(2):151-2.

24. Snels IA, Beckerman H, Twisk JW, Dekker $\mathrm{JH}$, Peter De Koning, Koppe PA, et al. Effect of triamcinolone acetonide injections on hemiplegic shoulder pain : A randomized clinical trial. Stroke. 2000;31(10):2396-401.

25. Chae J, Sheffler L, Knutson J. Neuromuscular electrical stimulation for motor restoration in hemiplegia. Top Stroke Rehabil. 2008;15(5):412-26.

26. Hara Y, Ogawa S, Tsujiuchi K, Muraoka Y. A home-based rehabilitation program for the hemiplegic upper extremity by power-assisted functional electrical stimulation. Disabil Rehabil. 2008;30(4):296-304.

27. Yu DT, Chae J, Walker ME, Fang ZP. Percutaneous intramuscular neuromuscular electric stimulation for the treatment of shoulder subluxation and pain in patients with chronic hemiplegia: a pilot study. Arch Phys Med Rehabil. 2001; 82(1):20-5.

28 Kumar R, Metter EJ, Mehta AJ, Chew T. Shoulder pain in hemiplegia. The role of exercise. Am J Phys Med Rehabil. 1990;69(4):205-8.

29. Lim JY, Koh JH, Paik NJ. Intramuscular botulinum toxin-A reduces hemiplegic shoulder pain: a randomized, double-blind, comparative study versus intraarticular triamcinolone acetonide. Stroke. 2008;39(1):126-31.

30. de Boer KS, Arwert HJ, de Groot JH, Meskers $C G$, Mishre AD, Arendzen JH. Shoulder pain and external rotation in spastic hemiplegia do not improve by injection of botulinum toxin $A$ into the subscapular muscle. J Neurol Neurosurg Psychiatry. May 2008;79(5): 581-3. 
31. Chironna RL, Hecht JS. Subscapularis motor point block for the painful hemiplegic shoulder. Arch Phys Med Rehabil. 1990;71(6):428-9.

32. Lorish TR, Sandin KJ, Roth EJ, Noll SF. Stroke rehabilitation. 3. Rehabilitation evaluation and management. Arch Phys Med Rehabil. May 1994;75(S):47-51.

33. Griffin J, Reddin G. Shoulder pain in patients with hemiplegia. Phys Ther.1981;61:1041.

34. Roy CW, Shoulder pain in hemiplegia: a literature review. Clin Rehabi.1988;2:35-44.

35. Inaba MK, Piorkowski M. Ultrasound in treatment of painful shoulders with hemiplegia. Phys Ther 1080;52:737-41.

36. Lee JM, Warren MP. Cold therapy in rehabilitation. Publisher Bell \& Hyman, London,1978(Citation).

37. Brudny J. New orthosis for the treatment of hemiplegic shoulder subluxation. Orthotics and Prosthetics, 1985; 39:14-20.

38. Sodring KM. Upper extremity for stroke patients. Int J Rehabil Res. 1980; 3:33-38.

39. Hanger HC, Whitewood P, Brown G, Ball MC, Harper J, Cox R, et al. A randomized controlled trial of strapping to prevent poststroke shoulder pain.ClinRehabil. Aug 2000;14(4):370-80.

40. Schleenbaker RE, Mainous AG 3rd. Electromyographic biofeedback for neuromuscular reeducation in the hemiplegic stroke patient: a meta-analysis. Arch Phys Med Rehabil. Dec 1993;74(12):1301-4.

41. Basmajian JV, Gowland CA, Finlayson MA, Hall AL, Swanson LR, Stratford PW, et al. Stroke treatment: comparison of integrated behavioral-physical therapy vs traditional physical therapy programs. Arch Phys Med Rehabil. May 1987;68(5 Pt 1):267-72.

42. Dickstein R, Hocherman S, Pillar T, Shaham $R$. Stroke rehabilitation. Three exercise therapy approaches. Phys Ther. 1986;66(8):1233-8.

43. Ernst E. A review of stroke rehabilitation and physiotherapy. Stroke. 1990; 21(7):1081-5.
44. Logigian MK, Samuels MA, Falconer J, Zagar R. Clinical exercise trial for stroke patients. Arch Phys Med Rehabil. 1983;64(8):364-7.

45. Salter J, Camp Y, Pierce LL, Mion LC. Rehabilitation nursing approaches to cerebrovascular accident: a comparison of two approaches. Rehabil Nurs.1991;16(2): 62-6.

46. Wagenaar RC, Meijer OG, van Wieringen PC, Kuik DJ, Hazenberg GJ, Lindeboom J, et al. The functional recovery of stroke: a comparison between neuro-developmental treatment and the Brunnstrom method. Scand J Rehabil Med. 1990;22(1):1-8.

47. Wolf SL, Lecraw DE, Barton LA, Jann BB. Forced use of hemiplegic upper extremities to reverse the effect of learned nonuse among chronic stroke and head-injured patients. Exp Neurol. May 1989;104(2):125-32.

48. Taub E, Miller NE, Novack TA, Cook EW , Fleming WC, Nepomuceno CS, et al. Technique to improve chronic motor deficit after stroke. Arch Phys Med Rehabil. 1993;74(4):347-54.

49. Carr EK, Kenney FD. Positioning of the stroke patient: a review of the literature.Int J Nurs Stud. Nov 1992;29(4):355-69.

50. Brandstater ME. Stroke rehabilitation. In: DeLisa JA, Gans BM, eds. Rehabilitation Medicine: Principles and Practice. 3rd ed. Philadelphia, Pa: Lippincott-Raven; 1998:1165-89.

51. Cailliet R. The shoulder in the hemiplegic patient. In: Shoulder Pain. 3rd ed. FA Davis; 1991:193-226.

52. Van Buskirk C, Webster D. Prognostic value of sensory deficit in rehabilitation of hemiplegics. Neurology. 1955;5(6):407-11.

53. Wanklyn P, Forster A, Young J. Hemiplegic shoulder pain (HSP): Natural history and investigation of associated features. Disabil Rehabil. 1996;18(10):497-501. 